\title{
Alkali and Alkaline Earth Metal \\ Complexes as Versatile \\ Catalysts for Ring-Opening \\ Polymerization of Cyclic Esters
}

Jayeeta Bhattacharjee, ${ }^{[a]}$ Alok Sarkar, ${ }^{[b]}$ and Tarun K. Panda*[a] 
Abstract: Biodegradable polyesters such as poly( $\varepsilon$-caprolactone) (PCL) and poly(lactic acid) (PLA) have been considered for use in several areas, such as drug delivery devices, sutures, tissue engineering, and GBR membranes, due to its bio-renewability, biodegradability, and biocompatibility. Several synthetic techniques for the preparation of polyesters have been reported in the literature, amongst which the ring-opening polymerization (ROP) of cyclic esters is the most efficient. A convenient approach to access iso-selective PLAs is polymerization of racemic lactide (rac-LA), which shows excellent stereoregularity without the need for costly chiral auxiliaries or ligands. In this paper, we review a series of methods that have been practiced to the synthesis of biodegradable polyesters from various cyclic monomers using alkali and alkaline earth metal complexes as efficient catalysts.

\section{Introduction}

Aliphatic polyesters continue to be a promising class of polymeric materials ${ }^{[1-4]}$ due to their excellent biodegradability and biocompatibility, which makes them a suitable and environmentally friendly alternative to conventional oil-based petrochemical materials (plastic). In addition, unlike petrochemical materials which are predominantly derived from rapidly depleting fossil feedstock, polyesters can be synthesized from monomers derived from renewable resources. Therefore, replacing petrochemical polymers with polyesters is an interesting strategy to address the world's most debated environmental problems caused by rapid depletion of fossil feedstock and disposal of plastic products. Further, environmental decomposition of aliphatic polyesters produces only water and carbon dioxide, which serve as feedstock for photosynthesis, thus closing the carbon cycle loop. Aliphatic polyesters are conveniently synthesized through the ring-opening polymerization (ROP) of cyclic esters. ${ }^{[5-7]}$ Although these reactions are driven by the release of excessive ring strain in the esters' cyclic structures, ${ }^{[5]}$ a catalyst is typically required to initiate the polymerization. Apart from initiating polymerization, catalysts also play a crucial role in controlling the molecular weight, polydispersity, microstructure, and end group of the resulting polymers. The fact that a polyester with better control over chain length and microstructure (viz., polylactide or PLA) exhibits superior thermal, mechanical, and biodegradable properties has always been the basis for developing newer catalysts in this field. An extensive research effort has been undertaken in the last few years to develop catalysts that can allow the synthesis of polyesters with very precise control over architecture. Till date, the polymerization of cyclic esters has been studied using a wide variety of catalysts including organocatalysts, ${ }^{[8-10]}$ various chiral/achiral ligands supported metal precursors such as complexes of $\mathrm{Sn},{ }^{[11,}{ }^{12]} \mathrm{Al},{ }^{[13-15]} \mathrm{Zn},{ }^{[16,17]} \mathrm{Mg},{ }^{[18,19]} \mathrm{Fe},{ }^{[20,}{ }^{[1]} \mathrm{Ti},{ }^{[22,23]}$ In, ${ }^{[24]} Y_{,}{ }^{[25]}$ lanthanide-initiators. ${ }^{[30,31]}$ Even a series of reviews which discuss the progress in this field, especially racemic lactide (rac-LA) are available, ${ }^{[32-46]}$ greater part of these articles cover the f-block and d-block metal complexes for ROP or stereoselective polymerization. Articles focusing on main group metal complexes are rather limited. However, with polyesters being increasingly explored in sophisticated applications involving packaging of medicine and food, there has recently been a considerable shift toward the development of new catalysts based on less toxic and less harmful organo-metals. The use of ubiquitous metals, instead of rare metals, is preferred because as the term suggests, availability of rare metals is limited, and their exhaustion could lead to serious problems. On the other hand, alkali metals such as lithium, sodium, potassium, cesium, and alkaline earth metals such as calcium, strontium, and barium are some of the most abundant metals in nature and are easily available in the sea and in the earth's crust. Recently, an interesting review published by Sun and co-workers summarized the progress in this field, particularly when group 1 and 2 metal complexes were used. ${ }^{[28]}$ Therefore, in this report, we spotlight on contemporary progress made in the biodegradable polyesters using this latter class of metal complexes.

Jayeeta Bhattacharjee obtained her Master of Science in Chemistry from the University of Kalyani in 2012 in the area of organic chemistry. She joined the Department of Chemistry at the Indian Institute of Technology (IITH), India, as a doctoral student at under the supervision of Prof. Tarun K. Panda in 2013. She was awarded the doctorate in 2018 in the area of organometallic chemistry and catalysis. Dr. Bhattacharjee joined the working group of Prof. Dr. Matthias Tamm at Technische Universität Braunschweig, Germany as a postdoctoral fellow in 2019. Her research area involves catalytic applications promoted by earth-abundant and environment metals using carbine phosphinedene complexes.

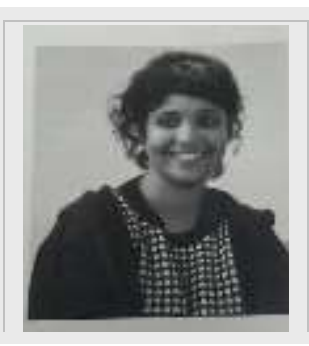

Alok Sarkar obtained his Master of Science in Chemistry from IIT Kharagpur in 2003 and received his doctorate from City University of New York, USA in 2007 under the supervision of Professor Bhanu P.S. Chauhan in Catalysis and Polymer Chemistry. Shortly after completing Ph.D., Dr. Sarkar joined William Paterson University, USA as an Adjunct Faculty Professor in the Department of Chemistry. In 2008, he returned to India to join Momentive Performance Materials Pvt. Ltd. (formerly known as GE), Bengaluru, as a Research Scientist. He was promoted to Lead Scientist in January 2014, and since January 2020, he is holding the position of Senior Scientist in the same company. His principal research interests include the development of high-performance materials for delivering differentiating benefits across various industry segments. 
Tarun K. Panda obtained his Master of Science in Chemistry from IIT, Kanpur in 2002 and received his Dr. rer. nat from Freie Universität Berlin, Germany in 2005 under the supervision of Prof. Dr. Peter W. Roesky in the area of organometallic chemistry. Dr. Panda joined the working group of Prof. Dr. Matthias Tamm at Technische Universität Braunschweig, Germany as a postdoctoral fellow in 2006. He was awarded the Japan Society for the Promotion of Science (JSPS) postdoctoral fellowship in 2008 to work with Prof. Kazushi Mashima in the Graduate School of Engineering, Osaka University, Japan. In 2010, he returned to

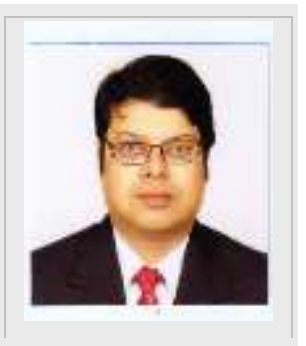
India to join the Department of Chemistry, Indian Institute of Technology Hyderabad (IITH) India as Assistant Professor. He was promoted to Associate Professor in 2015 and since May 2019, he is holding the position of Professor at the same Institute. He has been awarded the CRSI bronze medal 2021 for his significant contribution to Chemistry. His principal research interests include the development of well-defined earth-abundant, non-toxic, and environmentally benign metal complexes using noncyclopentadienyl-based ligands and their exploitation in homogeneous catalysis under ambient reaction conditions.

Some features of alkali and alkaline earth metals that are quite attractive from the perspective of catalyst design are: (a) low electron affinity, which means ligands to these metals can offer their electrons more easily to activate the substrate, and (b) extremely large ionic radius, which helps these metals to adopt different coordination sites depending upon the nature of the ligands (c) stable oxidation states of +1 (alkali metal) or +2 (alkaline earth metal).

\section{Alkali metal complexes}

Since PLA is used as a biomaterial, using toxic metals as catalysts to synthesize PLA is not preferred, as metal residues are very difficult to remove from polymers. With the push toward more environmentally-safe metal centers, group 1 elements have proved as the better alternatives in the ROP of rac-LA. In general, lithium, sodium, and potassium based catalysts have intrigued attention, as highly iso-selective catalysts based on these metals for the ROP of rac-LA have proved to be challenging under mild conditions. The following sections detail major advances in the development of iso-selective catalysts used in the ROP of rac-LA.

\subsection{Crown ether-supported alkali metal complexes}

For several decades, alkali metal complexes containing bulky crown-ether types of ligands have been the most familiar catalysts in this field and can initiate the ROP of lactides. Wu et al. reported the synthesis and characterization of a series of novel lithium, sodium, and potassium crown-ether complexes, bearing bulky mono-phenolate ligands $(\mathbf{1}, \mathbf{2}, \mathbf{5 - 7}, \mathbf{1 0 - 1 7}, \mathbf{1 8 - 2 0}),{ }^{[47,49,51-53]}$ naphthalenolate ligands $(3-4),{ }^{[48]}$ and chiral binolate $(8-9)^{[50]}$ ligands and used them in the ROP of rac-LA (Scheme 1). The steric bulkiness as well as electronic properties of these catalysts have introduced remarkable effects on their catalytic activity. All the complexes act as highly iso-selective and active catalysts for the controlled ROP of rac-LA at low temperatures. For complex $\mathbf{1}$, $P_{\mathrm{m}}$ value up to 0.87 was achieved when the ratio of $[\mathrm{rac}-$ $\mathrm{LA}]_{0}:[1]_{0}:[\mathrm{BnOH}]_{0}$ in THF at $-60{ }^{\circ} \mathrm{C}$ was $400: 1: 1$ (Table 1, entry 1 ). All the other complexes also act as good iso-selective catalysts in the polymerization of rac-LA with $P_{\mathrm{m}}$ values of $0.72-0.82$ at low temperatures (Table 1, entry 2, 5-10). The best iso-selectivity value of $P_{\mathrm{m}}=0.94$ was achieved by the potassium complex (10), with a ratio of $[\mathrm{rac}-\mathrm{LA}]_{0}:[10]_{0}:[\mathrm{BnOH}]_{0}$ of $200: 1: 1$ at a decreased reaction temperature of $-70^{\circ} \mathrm{C}$ (Table 1 , entry 7 ). It should also be noted that the molecular weight of the polymers in some cases is lower than the calculated one which may result from some transesterification reactions.

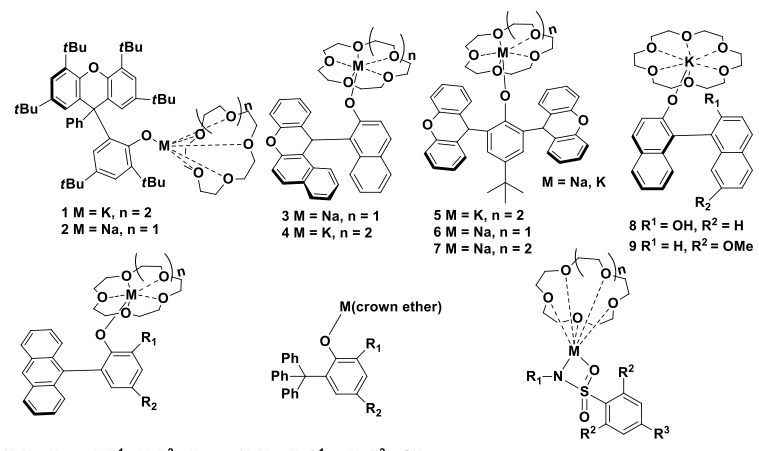

$10 \mathrm{M}=\mathrm{K}, \mathrm{n}=2, \mathrm{R}^{1}=\mathrm{H}, \mathrm{R}^{2}=\mathrm{H} \quad 18 \mathrm{M}=\mathrm{K}, \mathrm{R}^{1}=\mathrm{H}, \mathrm{R}^{2}=\mathrm{CH}_{3}, 21 \mathrm{M}=\mathrm{Na}, \mathrm{n}=1, \mathrm{R}_{1}=\mathrm{DIPP}, \mathrm{R}_{2}, \mathrm{R}_{3}=\mathrm{PPr}$

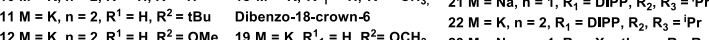

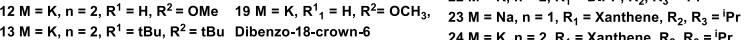

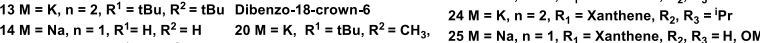
$\begin{array}{lll}14 \mathrm{M}=\mathrm{Na}, \mathrm{n}=1, \mathrm{R}^{1}=\mathrm{H}, \mathrm{R}^{2}=\mathrm{H} & 20 \mathrm{M}=\mathrm{K}, \mathrm{R}^{1}=\mathrm{HBu}, \mathrm{R}^{2}=\mathrm{CH}_{3}, & 25 \mathrm{M}=\mathrm{Na}, \mathrm{n}=1, R_{1}=\text { Xanthene, } R_{2}, R_{3}=\mathrm{H}, \text { OMe } \\ 15 \mathrm{M}=\mathrm{Na} n=1, R^{1}=\mathrm{H}, \mathrm{R}^{2}=\mathrm{tBu} & \text { Dibenzo-18-crown-6 } & 26 \mathrm{M}=\mathrm{Na}, \mathrm{n}=1, R_{1}=\text { Xanthene, } R_{2}, R_{3}=\mathrm{H}, \mathrm{Me}\end{array}$

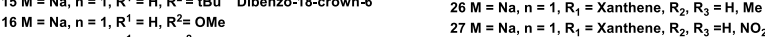
$17 \mathrm{M}=\mathrm{Na}, \mathrm{n}=1, \mathrm{R}^{1}=\mathrm{tBu}, \mathrm{R}^{2}=\mathrm{tBu}$
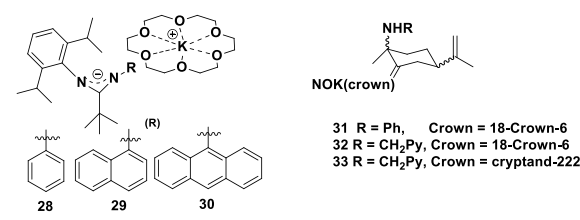

Scheme 1. Crown ether-supported alkali metal complexes.

Table 1. Best polymerization results of rac-LA catalyzed by crown ethersupported alkali metal complexes.

\begin{tabular}{|l|l|l|l|l|l|l|l|}
\hline $\begin{array}{l}\text { En } \\
\text { try }\end{array}$ & Cat & $\begin{array}{l}\text { Time } \\
(\mathrm{h}: \mathrm{m})\end{array}$ & $\begin{array}{l}{[\mathrm{LA}]_{0} /[\mathrm{Cat}]_{0}} \\
/[\mathrm{BnOH}]_{0}\end{array}$ & $\begin{array}{l}\text { Con } \\
(\%)^{[\mathrm{e}]}\end{array}$ & $\begin{array}{l}M_{\mathrm{n} \exp } \\
\left(\mathrm{gmol}^{-1}\right)^{[\mathrm{f}]}\end{array}$ & PDI & $P_{\mathrm{m}}{ }^{[\mathrm{g}]}$ \\
\hline $1^{[\mathrm{a}, \mathrm{d}]}$ & 1 & 0.05 & $400 / 1 / 1$ & 76 & 7000 & 1.08 & 0.87 \\
\hline $2^{[\mathrm{a}, \mathrm{d}]}$ & 2 & 0.05 & $300 / 1 / 10$ & 99 & 4500 & 1.08 & 0.87 \\
\hline $3^{[\mathrm{b}, \mathrm{c}]}$ & 4 & 0.30 & $1000 / 1 / 1$ & 98 & 70400 & 1.17 & 0.75 \\
\hline $4^{[\mathrm{b}, \mathrm{c}]}$ & 5 & 0.10 & $100 / 1 / 1$ & 95 & 13100 & 1.07 & 0.77 \\
\hline $5^{[\mathrm{b}, \mathrm{d}]}$ & 5 & 2.00 & $100 / 1 / 1$ & 99 & 14000 & 1.08 & 0.82 \\
\hline $6^{[\mathrm{b}, \mathrm{d}]}$ & 8 & 5.25 & $100 / 1 / 1$ & 74 & 10800 & 1.05 & 0.80 \\
\hline $7^{[\mathrm{b}, \mathrm{d}]}$ & 10 & 16.00 & $200 / 1 / 1$ & 93 & 26900 & 1.05 & 0.94 \\
\hline $8^{[\mathrm{b}, \mathrm{d}]}$ & 12 & 4.00 & $100 / 1 / 1$ & 94 & 13600 & 1.04 & 0.91 \\
\hline $9^{[\mathrm{b}, \mathrm{d}]}$ & 13 & 12.00 & $100 / 1 / 1$ & 96 & 14000 & 1.09 & 0.89 \\
\hline $10^{[\mathrm{b}, \mathrm{d}]}$ & 18 & 00.01 & $100 / 1 / 1$ & 88 & 12600 & 1.05 & 0.89 \\
\hline $11^{[\mathrm{b}, \mathrm{d}]}$ & 23 & 24.00 & $100 / 1 / 1$ & 87 & 12700 & 1.04 & 0.84 \\
\hline $12^{[\mathrm{b}, \mathrm{c}]}$ & 23 & 12.00 & $100 / 1 / 1$ & 97 & 30400 & 1.41 & 0.63 \\
\hline $13^{[\mathrm{b}, \mathrm{d}]}$ & 29 & 00.30 & $400 / 1 / 1$ & 92 & 52800 & 1.05 & 0.90 \\
\hline $14^{[\mathrm{b}, \mathrm{d}]}$ & 32 & 00.10 & $100 / 1 / 10$ & 100 & 1100 & 1.05 & 0.93 \\
\hline
\end{tabular}

Reactions were performed in [a] THF or [b] Toluene, at [c] room temperature or [d] low temperature $\left(0^{\circ} \mathrm{C}\right.$ to $\left.-70^{\circ} \mathrm{C}\right)$ depends upon the catalyst. [e] Determined by ${ }^{1} \mathrm{H}$ NMR spectroscopy. [f] Measured by GPC. [g] Determined by analysis of all of the tetrad signals in the methine region of the homonucleardecoupled ${ }^{1} \mathrm{H}$ NMR spectrum. 
In addition, Wu and Cano et al. demonstrated the synthesis of crown-ether or cryptand alkali metal compounds, with bichelating sulfonamides (21-27), ${ }^{[53]}$ ion-paired amidinate $(\mathbf{2 8 - 3 0}),{ }^{[54]}$ and terpene-derived oximate ligands $(\mathbf{3 1 - 3 3})^{[55]}$ for the ROP of racLA. Complexes 29-33 can effectively catalyze the ROP of rac-LA in the presence of 1 equivalent of $\mathrm{BnOH}$ at room temperature. However, compared to phenolate sodium and potassium crownether complexesm (4-5), the sulfonamide complexes (21-27) show moderate activity at room temperature (Table 1, entry 3, 4, 11). Complexes 28-33 act as active catalysts in toluene at -70 ${ }^{\circ} \mathrm{C}$, giving nearly complete conversions and producing highly isotactic PLA with remarkable $P_{\mathrm{m}}$ values in the range $0.85-0.93$ temperature (Table 1, entry 13-14).

\subsection{P-based coordinated alkali metal complexes}

Recently, our group introduced several alkali metal complexes (34-39) formed by $\mathrm{N}$-(2-fluoro/2-nitrophenyl)-P,P-diphenylphosphinoselenoic amide ligands in the ROP of rac-LA. 1 equivalent of either lithium, sodium, or potassium bis(trimethylsilyl)amide was reacted with diphenylphosphinoselenoic amide ligands in THF afforded the respective monomeric alkali metal complexes of molecular composition [ $\left.\left(\mathrm{Ph}_{2} \mathrm{PNC}_{6} \mathrm{H}_{4} \mathrm{X}\right) \mathrm{M}(\mathrm{THF})_{\mathrm{y}}\right]$ (34-39) in excellent yields (Scheme 2). Both the $\mathrm{Na}$ and $\mathrm{K}$ complexes not only showed competent activity in the ROP of rac-LA but were also very active in the ROP of $\varepsilon-C L$ and $\delta$-VL. In alkali metal chemistry, this is the first example of a polymerization reaction not being dependent upon external initiators like alcohol. The phosphorus-chalcogen ( $\mathrm{S}, \mathrm{Se}$ ) double bonds of the above-mentioned complexes start the initiation step. Both the lithium complexes (34 and 35) afforded only $50 \%$ conversion of the $\varepsilon$-CL monomer to the particular PCL polymer even after the reaction mixture was stirred for 24 hours, due to the small size of the dynamic metal centers. When the sodium complexes (36 and 37 ) were used, rac-LA is fully converted to PLA in a period of one hour, up to a monomer-toinitiator ratio of $500: 1$ at room temperature, whereas with the potassium complexes (38 and $\mathbf{3 9}$ ), 99\% conversion was obtained within a mere 30 minutes indicating much faster reaction rate. Even increasing the monomer-to-initiator ratio up to 1000:1, the polymerization reaction completed within 1 hour given $95 \%$ conversion using 39 as catalyst with good molecular weight distribution (Table 2, entry 5). Further, both the sodium and potassium complexes containing nitro-substituted diphenylphosphinoselenoic amide ligand (37 and 39) showed faster activity than the corresponding fluoro-substituted ligand (36 and 38). A flexible six-membered metallocyclic ring formed due to the larger nitro group with active metal sites compared a crowded five-membered ring around metal sites in the fluoro group presumably aids in providing additional free space around the metal ion, causing the metal-selenium bond to be more labile in the initiation step. The molecular weights of most polymer samples were fully consistent with their calculated values, having narrow molecular weight distributions. All the catalysts were isotactic. The sodium complexes (36 and 37 ) showed higher isoselectivity with $P_{\mathrm{m}}=0.71-0.78$ (Table 2 , entry $1-2$ ) than the potassium complexes (38 and 39) (Table 2, entry 3-4) with $P_{\mathrm{m}}=$ 0.61-0.69 at room temperature, indicating that better control over stereoselectivity in the polymerization process is suseptable to both the ligand environments and size of the active metal centers. ${ }^{56}$

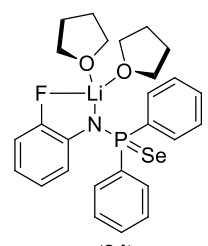

(34)

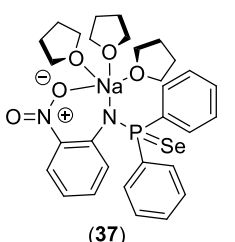

(37)

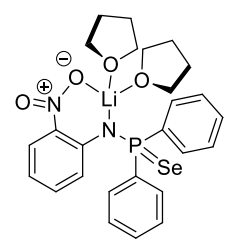

(35)

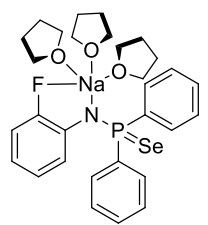

(36)
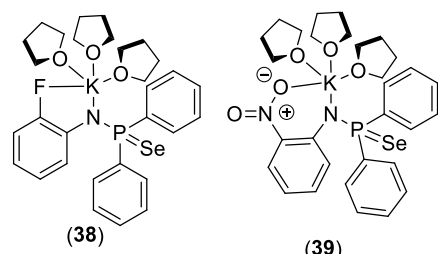

(39)

Scheme 2. Alkali metal complexes containing $\mathrm{P}(\mathrm{S})$ and $\mathrm{P}(\mathrm{Se})$.

Table 2. Best polymerization results of rac-LA catalyzed by alkali metal complexes of phosphinoselenoic amide ligands.

\begin{tabular}{|l|l|l|l|l|l|l|l|}
\hline Entry & Cat & $\begin{array}{l}\text { Time } \\
(\mathrm{h}: \mathrm{m})\end{array}$ & $\begin{array}{l}{[\mathrm{LA}]_{0} /} \\
{[\mathrm{Cat}]_{0}}\end{array}$ & Con(\% $)^{[\mathrm{a}]}$ & $\begin{array}{l}M_{\mathrm{n} e x p} \\
\left(\mathrm{gmol}^{-1}\right)^{[\mathrm{b}]}\end{array}$ & PDI & $P_{\mathrm{m}}{ }^{[\mathrm{c}]}$ \\
\hline 1 & 36 & 01.30 & $200 / 1$ & 91 & 27900 & 1.33 & 0.75 \\
\hline 2 & 37 & 01.00 & $100 / 1$ & 93 & 14600 & 1.34 & 0.78 \\
\hline 3 & 38 & 0.30 & $100 / 1$ & 99 & 14900 & 1.15 & 0.68 \\
\hline 4 & 39 & 0.45 & $400 / 1$ & 95 & 53900 & 1.35 & 0.69 \\
\hline 5 & 39 & 1.10 & $1000 / 1$ & 95 & 140000 & 1.29 & 0.67 \\
\hline
\end{tabular}

Conditions: Reactions were carried out in toluene, at $25^{\circ} \mathrm{C}$, [catalyst] $=1 \mathrm{mM}$. [a] Determined by ${ }^{1} \mathrm{H}$ NMR spectroscopy. [b] Measured by GPC. [c] Determined by analysis of all of the tetrad signals in the methine region of the homonucleardecoupled ${ }^{1} \mathrm{H}$ NMR spectrum.
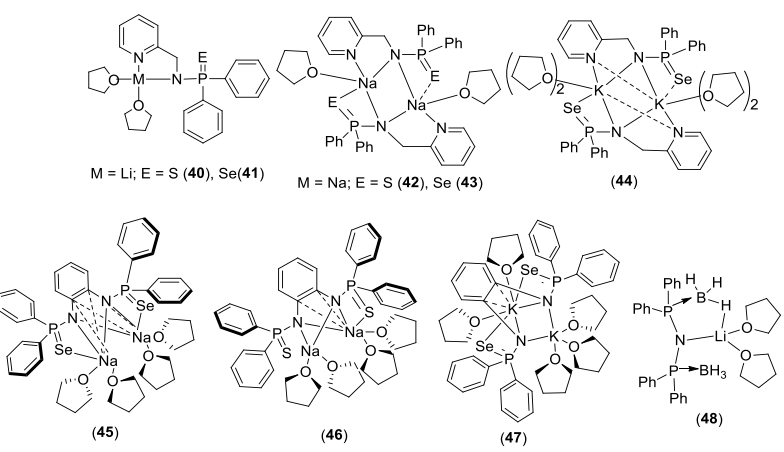

Scheme 3. Alkali metal complexes containing $P(S), P(S e)$, and $P(B)$.

Further, our group introduced a series of monomeric lithium complexes $(\mathbf{4 0}-\mathbf{4 1}, \mathbf{4 8})$, dimeric sodium complexes (42-44), and potassium (45-47) complexes bearing 2-picolylaminod iphenylphosphane chalcogenide 1,2-phenylene (bis-diphenylphosphino-thioic/selenoic amines) and bis(diphenylphosphinoborane)amido ligands. ${ }^{[57-59]}$ Even the Ae metal complexes with these ligands have proved as superior iso-selective catalysts in rac-LA and lactone chemistry, the corresponding alkali metal complexes are not competent catalysts for the ROP of rac-LA (Scheme 3). In most cases, a low conversioner (<30\%) were 
achieved for monomer:catalyst ratio of 50 along with lower molecular weight of the polymers than its calculated values which may resulted from some transesterification reactions.

\section{Alkaline earth metal complexes}

Catalysis based on heavier alkaline earth metals has not been much explored for its catalytic potential. Examples in polymerization chemistry are mainly limited to Lewis-acidic catalysis with late main group elements such as $\mathrm{Al}$, In, or $\mathrm{Sn}$ as the catalysts. As these alkaline earth metal-based complexes show typical organolanthanide-like reaction behavior, such as $\sigma$ bond metathesis and addition to saturated bonds, it is not surprising that this compound class can be exploited in several types of catalytic reactions. The main challenge in the development of this catalyst, based on heavier alkaline earth metal complexes, is the propensity of heteroleptic compounds of the form LMX to undergo Schlenk-like solution redistribution reactions and convert to homoleptic compounds $L_{2} M$ and $M X_{2}$. The latter species are often polymeric and demonstrate low solubility in non-coordinating solvents, while the former species are kinetically stabilized and unreactive. The solution redistribution reaction results in the formation of a mixture from a potentially catalytically active species and may result in the loss of any ligand control reactivity. This problem becomes increasingly important on descending down the group and, for a given ancillary ligand set, the tendency toward solution redistribution of heteroleptic group 2 organometallics, $L M X$, to $\mathrm{MX}_{2}$ and $\mathrm{L}_{2} \mathrm{M}$ increases across the series $\mathrm{M}=\mathrm{Mg}<\mathrm{Sr}<\mathrm{Ca}<\mathrm{Ba}$. To overcome this problem, several research groups have proposed that introducing a sterically demanding monoanionic ligand set into heavier alkaline earth metal chemistry can slow down Schlenk-like solution redistribution reactions due to kinetic stabilization of heteroleptic complexes. A recent example is the work of Chisholm et al., who reported the isolation and characterization of the $\beta$-diketiminato-stabilized calcium amide and a tris(pyrazolyl-borate) stabilized analog, along with their application in the ROP of rac-LA to form heterotactic PLA. ${ }^{[60]}$ Among alkaline earth metals $(\mathrm{Mg}, \mathrm{Ca}, \mathrm{Sr}$, and $\mathrm{Ba})$, magnesium was extensively studied by Grignard; it is exceptional and plays a significant role in synthetic organic and inorganic chemistry. ${ }^{[61]}$ In this way, the reactivity of resulting metal complexes can be specifically tailored to allow applications in areas such as activation of small and poorly active molecules, homogeneous catalysts, such as ROP of various cyclic esters, styrene, and dienes. As a result of these achievements from using heavier alkaline earth metals as well as their non-toxic nature (compared to that of several precious metals and heavier metals), a number of research groups have been attracted to working with them. Thus, several nitrogen-based ancillary ligands have successfully been introduced to the heavier alkaline earth metal coordination sphere to stabilize these highly oxophilic and electropositive metals.

3.1 Alkaline earth metal complexes with phenoxides and alkoxides
Calcium is an inexpensive, biocompatible, and kinetically labile metal ion. Calcium finds extensive industrial use in the production of polyoxygenates such as poly(ethylene oxide), PEO, and polypropylene oxide. Chisholm and coworkers introduced the monomeric heteroleptic calcium amide and alkoxide complexes such as tris-(pyrazolyl)borate calcium complexes (49 and 50) to the ROP of lactides (Scheme 4). ${ }^{[60]}$ Both complexes are exceptionally active for lactide polymerization, and display $90 \%$ heteroselectivity in the ROP of rac-LA in THF at room temperature. A conversion of $90 \%$ was achieved in one minute $\left([\mathrm{LA}]_{0} /[49]_{0}=200, M_{\mathrm{n}}=37.8 \mathrm{~kg} \mathrm{~mol}^{-1}, \mathrm{PDI}=1.74\right.$ and $[\mathrm{LA}]_{0} /[50]_{0}$ $\left.=200, \mathrm{M}_{\mathrm{n}}=40.1 \mathrm{~kg} \mathrm{~mol}^{-1}, \mathrm{PDI}=1.68\right)($ Table 3 , entry 1-2). In 2013, Mountfold et al. reported binuclear calcium (51) and strontium (52) complexes with the 2,4-di-tert-butylphenolate ligand as a catalyst in the ROP of rac-LA by using benzyl alcohol or benzylamine as a co-initiator (Scheme 4). Both complexes form atactic alcohol- or amine-terminated PLAs with a fair control over molecular weight via an activated monomer propagation mechanism. ${ }^{[62]}$ Numerous heteroleptic 2,6-di-tert-butyl-4methylphenolate (BHT) magnesium complexes (53-55) have been synthesized by treating $\left[(\mathrm{BHT}) \mathrm{MgBu}(\mathrm{THF})_{2}\right]$ with various alcohols (Scheme 4). All these complexes act as highly active catalysts in the ROP of rac-LA or $\varepsilon-\mathrm{CL}$. [(BHT)Mg(OBn) $\left.(\mathrm{THF})_{2}\right]$, which can be generated in situ by the interaction of $\mathrm{BnOH}$ with complex 53, almost completed the ROP of $\varepsilon$-caprolactone $(\varepsilon-\mathrm{CL})$ and $\mathrm{rac}$-LA within two minutes in the ([Monomer]/[Cat] $=200$, at $25^{\circ} \mathrm{C}$ (Table 3, entry 3). Meanwhile, DFT results indicated that a binuclear mechanism is more favorable toward the ROP of both lactones and lactides by these complexes. ${ }^{[63]}$

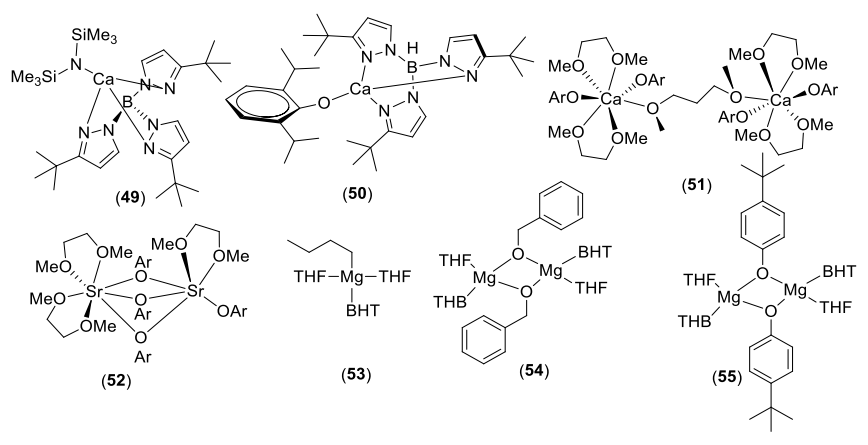

Scheme 4. ROP of cyclic esters catalyzed by alkaline earth metal phenoxide or alkoxide.

Table 3. Best polymerization results of rac-LA catalyzed by alkaline earth metal complexes with phenoxides and alkoxides ligands.

\begin{tabular}{|l|l|l|l|l|l|l|l|}
\hline Entry & Cat & $\begin{array}{l}\text { Time } \\
(\mathrm{h}: \mathrm{m})\end{array}$ & $\begin{array}{l}{[\mathrm{LA}]_{0} /} \\
{[\mathrm{Cat}]_{0}}\end{array}$ & $\begin{array}{l}\text { Con } \\
(\%)^{[\mathrm{d}]}\end{array}$ & $\begin{array}{l}M_{\mathrm{nexp}} \\
\left(\mathrm{gmol}^{-1}\right)^{[\mathrm{e}]}\end{array}$ & PDI & $P_{\mathrm{r}^{[\mathrm{f}]}}$ \\
\hline $1^{[\mathrm{a}]}$ & 49 & 00.01 & $200 / 1$ & 90 & 37800 & 1.74 & 0.90 \\
\hline $2^{[\mathrm{a}]}$ & 50 & 00.01 & $200 / 1$ & 90 & 40100 & 1.68 & 0.90 \\
\hline $3^{[\mathrm{b}, \mathrm{c}]}$ & 53 & 00.02 & $200 / 1$ & 95 & 25600 & 1.41 & - \\
\hline $4^{[\mathrm{a}]}$ & 54 & 00.10 & $200 / 1$ & 94 & 25400 & 1.38 & - \\
\hline
\end{tabular}

All reactions were performed in [a] THF or [b] $\mathrm{CH}_{2} \mathrm{Cl}_{2}$, at room temperature. [c] Activated by 1 eq. of $\mathrm{BnOH}$. [d] Determined by ${ }^{1} \mathrm{H}$ NMR spectroscopy. [e] Measured by GPC. [f] Determined by analysis of all of the isi and sis tetrad signals in the methine region of the homonucleardecoupled ${ }^{1} \mathrm{H}$ NMR spectrum. 
3.2 Alkaline earth metal complexes with some nitrogenbased ligands

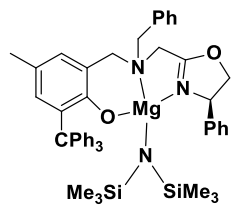

(56)

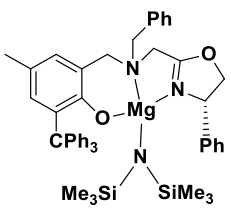

(57)

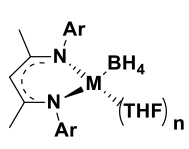
$=\operatorname{Sr}(59), n=2$
$M=C a(58), n=2$

Scheme 5. ROP of cyclic esters catalyzed by nitrogen-based bidentate alkaline earth metal complexes.

Table 4. Best polymerization results of rac-LA catalyzed by alkaline earth metal complexes of $\mathrm{N}$ based ligands.

\begin{tabular}{|l|l|l|l|l|l|l|l|}
\hline Entry & Cat & $\begin{array}{l}\text { Time } \\
(\mathrm{h}: \mathrm{m})\end{array}$ & $\begin{array}{l}{[\mathrm{LA}]_{0} /} \\
{[\mathrm{Cat}]_{0}}\end{array}$ & $\begin{array}{l}\text { Con } \\
(\%)^{[\mathrm{f}]}\end{array}$ & $\begin{array}{l}M_{\mathrm{n}} \exp \\
\left(\mathrm{gmol}^{1}\right)^{[\mathrm{g}]}\end{array}$ & PDI & $\begin{array}{l}P_{\mathrm{m}} \\
/ P_{\mathrm{r}}\end{array}$ \\
\hline $\left.1^{[\mathrm{h}]}, \mathrm{d}\right]$ & 56 & 03.00 & $500 / 1$ & 92 & 64500 & 1.08 & 0.78 \\
\hline $2^{[\mathrm{a}, \mathrm{c}, \mathrm{d}]}$ & 57 & 00.03 & $1000 / 1$ & 91 & 16000 & 1.62 & 0.73 \\
\hline $3^{[\mathrm{a}, \mathrm{c}, \mathrm{e}]}$ & $\begin{array}{l}56: 57 \\
(1: 1)\end{array}$ & 00.05 & $5000 / 1$ & 90 & 461000 & 1.26 & 0.80 \\
\hline $4^{[\mathrm{a}, \mathrm{d}]}$ & $\begin{array}{l}56: 57 \\
(1: 1)\end{array}$ & 02.00 & $500 / 1$ & 91 & 63000 & 1.09 & 0.84 \\
\hline $5^{[\mathrm{b}, \mathrm{c}]}$ & 58 & 01.30 & $100 / 1$ & 91 & 5350 & 1.79 & - \\
\hline $6^{[\mathrm{b}, \mathrm{c}]}$ & 60 & 00.05 & $20 / 1$ & 93 & 4200 & 1.46 & $0.86\left(P_{\mathrm{r}}\right)$ \\
\hline
\end{tabular}

Reactions were performed in [a] Toluene or [b] THF, at [c] room temperature or [d] low temperature $\left(-40^{\circ} \mathrm{C}\right)$ depends upon the catalyst. [e] Activated by 1 eq. of $\mathrm{PrOH}$. [f] Determined by ${ }^{1} \mathrm{H}$ NMR spectroscopy. [g] Measured by GPC. [h] Determined by analysis of all of the tetrad signals in the methine region of the homonucleardecoupled ${ }^{1} \mathrm{H}$ NMR spectrum.

Ma's research group reported chiral oxazolinyl aminophenoxide magnesium complexes (56-57) that act as superior catalysts, bringing together both enhanced activity and distinct sterioselectivity for the ROP of rac-LA in ambient temperature (Scheme 5) (Table 3, entry 1-2). Kinetic experiments performed on the polymerizations of D-LA, L-LA, and rac-LA determined an enantiomorphic site control mechanism to explain the isoselectivity. Using a racemic derivatives of complexes 56-57, semicrystalline stereoblock PLAs with exceptionally high molecular weights $\left(M_{n}\right.$ up to $461 \mathrm{~kg} \mathrm{~mol}^{-1}$ ) were produced with high activity levels which were considered to occur through polymeryl exchange processes (Table 4, entry 3). At a high molar ratio of $[\mathrm{rac}-\mathrm{LA}]_{0}:[\mathrm{Mg}]_{0}:[\mathrm{iPrOH}]_{0}=5000: 1: 1$, a racemic mixture of complexes $\mathbf{5 6}$ and $\mathbf{5 7}$ (in a 1:1 ratio) achieved $90 \%$ conversion in five minutes while maintaining good selectivity $\left(P_{m}=0.80\right)$. Both chirality of the ligand and the dinuclear nature of the active species applied compelling effects on the iso-selective control of these magnesium complexes in the ROP of rac-LA. ${ }^{[64]}$ The $\beta$ diketiminate-containing Ae metal tetrahydroborate complexes (58-60) were easily obtained by the treatment of $\left[\mathrm{K}\left\{\mathrm{HC}(\mathrm{C}(\mathrm{Me}) \mathrm{NAr})_{2}\right\}\right] \quad\left(\mathrm{Ar}=2,6-\mathrm{PPr}_{2} \mathrm{C}_{6} \mathrm{H}_{3}\right)$ with $\left[\mathrm{Mg}\left(\mathrm{BH}_{4}\right)_{2}\right]$, $\left[\mathrm{Ca}\left(\mathrm{BH}_{4}\right)_{2}(\mathrm{THF})_{2}\right]$ or $\left[\mathrm{Sr}\left(\mathrm{BH}_{4}\right)_{2}(\mathrm{THF})_{2}\right]$ (Scheme 5). The strontium complex (59) was obtained in low yields due to its relative unstable nature in solution. Complexes 59-60 are highly active in the ROP of $\varepsilon-C L$, forming dihydroxytelechelic PCL. Compound 60 was exceptionally active in the ROP of rac-LA, with complete monomer conversion achieved in two minutes at room temperature with $[\varepsilon-C L]_{0}:[M]_{0}=200: 1$, forming highly heterotactic PLA with acceptable agreement between calculated and measured $M_{\mathrm{n}}$ (Table 4, entry 6$)$. This level of performance is in accord with previous studies of alkoxide and amide initiators based on this metal and ligand class. ${ }^{[65]}$

\subsection{Alkyl Heteroscorpionate Magnesium Complexes}

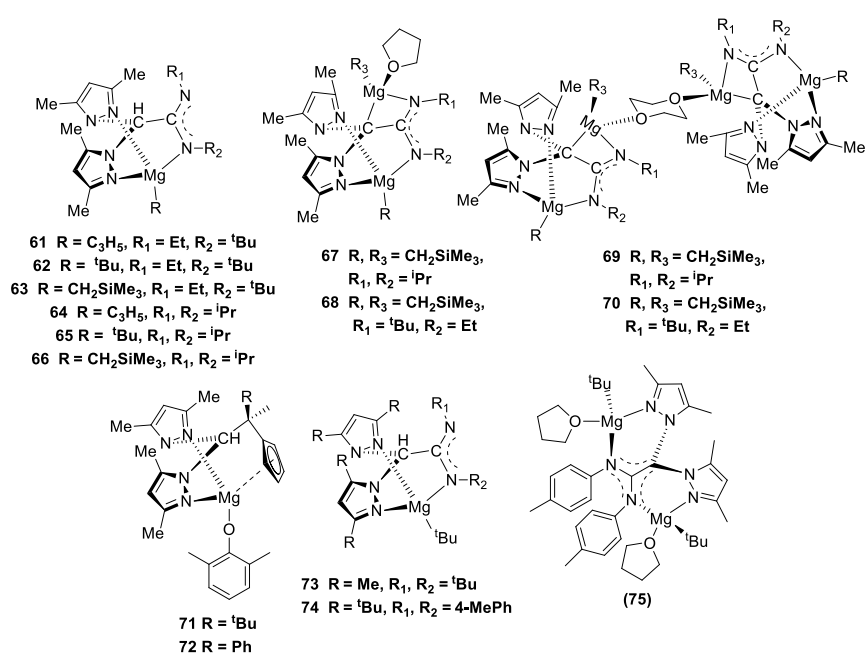

Scheme 6. ROP of cyclic esters catalyzed by alkyl heteroscorpionate magnesium complexes.

Table 5. Best polymerization results of rac-LA catalyzed by alkyl heteroscorpionate magnesium complexes.

\begin{tabular}{|l|l|l|l|l|l|l|l|}
\hline Entry & Cat & $\begin{array}{l}\text { Time } \\
(\mathrm{h}: \mathrm{m})\end{array}$ & $\begin{array}{l}{[\mathrm{LA}]_{0} /} \\
{[\mathrm{Cat}]_{0}}\end{array}$ & $\begin{array}{l}\text { Con } \\
(\%)^{[\mathrm{f}]}\end{array}$ & $\begin{array}{l}M_{\mathrm{n}} \exp \\
\left(\mathrm{gmol}^{1}\right)^{[\mathrm{g}]}\end{array}$ & PDI & $P_{\mathrm{s}}^{[\mathrm{h}]}$ \\
\hline $1^{[\mathrm{a}, \mathrm{d}]}$ & 66 & 00.45 & $100 / 1$ & 61 & 6600 & 1.44 & - \\
\hline $2^{[\mathrm{a}, \mathrm{d}, \mathrm{e}]}$ & 66 & 96.00 & $100 / 1$ & 93 & 12600 & 1.19 & - \\
\hline $3^{[\mathrm{b}, \mathrm{c}, \mathrm{e}]}$ & 67 & 00.07 & $200 / 1$ & 94 & 26000 & 1.08 & - \\
\hline $4^{[\mathrm{b}, \mathrm{d}]}$ & 70 & 05.00 & $200 / 1$ & 38 & 10200 & 1.10 & 0.78 \\
\hline $5^{[\mathrm{b}, \mathrm{c}]}$ & 74 & 01.00 & $100 / 1$ & 96 & 14000 & 1.09 & 0.85 \\
\hline $6^{[\mathrm{b}, \mathrm{c}]}$ & 75 & 03.00 & $100 / 1$ & 89 & 12500 & 1.09 & 0.80 \\
\hline
\end{tabular}

Reactions were performed in [a] Toluene or [b] THF, at [c] room temperature or [d] high temperature depends upon the catalyst. [e] L-lactide. [f] Determined by ${ }^{1} \mathrm{H}$ NMR spectroscopy. [g] The parameter $P_{\mathrm{s}}(\mathrm{s}=$ syndiotactic) is the probability of forming a new $\mathrm{s}$-dyad. $P_{\mathrm{s}}$ is the probability of syndiotactic (racemic) linkages between monomer units and is determined from the relative intensity in the tretrads obtained in the decoupled ${ }^{1} \mathrm{H}$ NMR.

Both fernandez-baeza et.al. and otero et.al. reported the synthesis, characterization and coordination ability of a series of alkyl heteroscorpionate magnesium complexes $\left(61-66,{ }^{[66]} 67\right.$ $\mathbf{7 0},{ }^{[67]} \mathbf{7 1 - 7 2},{ }^{[68]} \mathbf{7 3 - 7 5 ^ { [ 6 9 ] }}$ ) which act as good initiators for the stereoselective ROP of cyclic esters. All this complexes act as highly efficient single-component living initiators for the ROP of $\varepsilon$ caprolactone and L-lactides (Table 5, Entry 1-3). In the case of rac-LA polymerization, it formed highly heterotactic PLA under mild conditions (Table 5, Entry 4-6). Mononuclear compound 74, and dinuclear compound 75 can act as a highly efficient catalyst for the ROP of rac-LA (Table 5, entry 5-6). More interestingly, the most sterically hindered initiators 75 exhibit enhanced levels of 
heteroselectivity on the PLAs, with $P_{\mathrm{s}}$ values up to 0.85 at room temperature (Table 5, entry 6).

\subsection{Alkaline earth metal complexes with groups containing $P(\mathrm{Se}), \mathrm{P}(\mathrm{B})$, and $\mathrm{P}(\mathrm{S})$}

These ligand molecules in general represent a unique class of ligands that are quite different in several aspects from the previously reported one. They do not need any external initiator to initiate the polymerization step. While most existing ligands bind to metal ions through oxygen and nitrogen atoms, these newly designed ligands offer electronically enriched sulfur, selenium, or hydride to bind with metal center (Scheme 7).

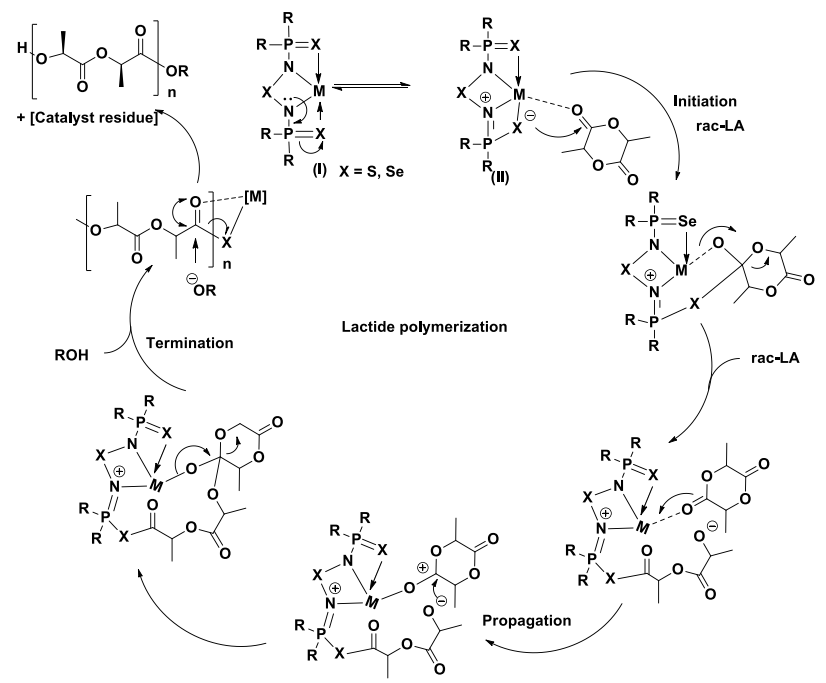

Scheme 7: A most plausible mechanism for Ae metal-promoted ROP or racLA.

Therefore, electrons in these complexes are readily available for nucleophilic attack on the carbonyl group of the lactide monomers Additionally, these complexes can be readily made by treating these ligands with metal silazide and metal iodide using a common synthetic approach. Therefore, synthesis of metal complexes using these ligands with various alkaline earth metal cations may provide access to a series of catalysts for use in the ROP of lactide under mild conditions.

The Ae metal complexes of bis-diphenylphosphinothioic/selenoic amine ligands $\left[\mathrm{E}=\mathrm{S}, \mathrm{X}=-\mathrm{C}_{6} \mathrm{H}_{4^{-}}, \mathrm{M}=\mathrm{Ca}(64), \mathrm{Sr}(65), \mathrm{Ba}(66)\right.$; $\mathrm{E}$ $=\mathrm{Se}, \mathrm{X}=-\mathrm{C}_{6} \mathrm{H}_{4^{-}}, \mathrm{M}=\mathrm{Ca}(67), \mathrm{Sr}(68), \mathrm{Ba}(69)$, and $\mathrm{E}=\mathrm{Se}, \mathrm{X}=-$ $\mathrm{C}_{2} \mathrm{H}_{4^{-}}, \mathrm{M}=\mathrm{Ca}(70), \mathrm{Sr}(71)$ and $\left.\mathrm{Ba}(72)\right]$ are synthesized by treating ligands with two moles of anhydrous $\left[\mathrm{KN}\left(\mathrm{SiMe}_{3}\right)_{2}\right]$ in $\mathrm{THF}$ to generate the corresponding potassium salt, which further reacts with anhydrous $\mathrm{Ael}_{2}(\mathrm{Ae}=\mathrm{Ca}, \mathrm{Sr}, \mathrm{Ba})$ to give rise to the corresponding Ae metal complexes (Scheme 8). ${ }^{[57,70]}$ The crystals of compounds 64-69 were obtained from a saturated THF and pentane solution at low temperatures, whereas compounds 70 72 were recrystallized from hot THF solutions.

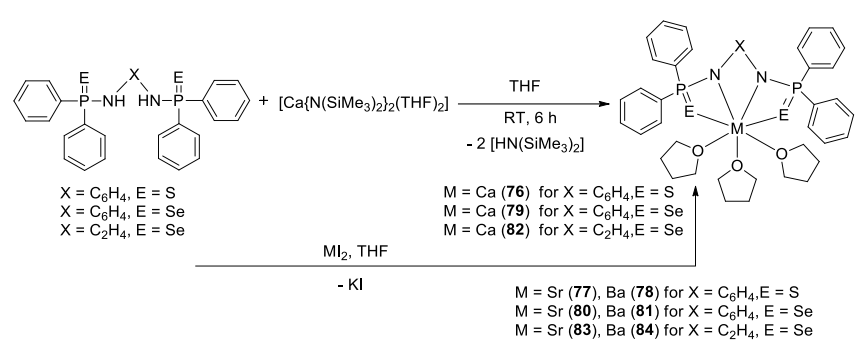

Scheme 8: Bis - $\mathrm{P}(\mathrm{S})$ and $\mathrm{P}(\mathrm{Se})$-containing alkaline earth metal complexes.

Table 6. Best polymerization results of rac-LA and nylon- 6 catalyzed by alkaline earth metal complexes of aminophosphine chalcogen and aminophosphine borane ligands.

\begin{tabular}{|l|l|l|l|l|l|l|l|}
\hline Entry & Cat & $\begin{array}{l}\text { Time } \\
(\mathrm{h}: \mathrm{m})\end{array}$ & $\begin{array}{l}{[\mathrm{LA}]_{0} /} \\
{[\mathrm{Cat}]_{0}}\end{array}$ & Con(\% $)^{[\mathrm{b}]}$ & $\begin{array}{l}M_{\mathrm{nexp}} \\
\left(\mathrm{gmol}^{-1}\right)^{[\mathrm{c}]}\end{array}$ & PDI & $P_{\mathrm{m}}{ }^{[\mathrm{d}]}$ \\
\hline 1 & 76 & 00.30 & $100 / 1$ & 99 & 15900 & 1.24 & 0.87 \\
\hline 2 & 79 & 00.30 & $100 / 1$ & 99 & 16700 & 1.53 & 0.83 \\
\hline 3 & 78 & 00.05 & $100 / 1$ & 99 & 14600 & 1.35 & 0.55 \\
\hline 4 & 81 & 00.03 & $100 / 1$ & 99 & 15900 & 1.21 & 0.52 \\
\hline 5 & 85 & 00.10 & $100 / 1$ & 98 & 15300 & 1.20 & 0.84 \\
\hline 6 & 86 & 00.10 & $100 / 1$ & 99 & 14800 & 1.15 & 0.80 \\
\hline 7 & 87 & 00.03 & $100 / 1$ & 99 & 13900 & 1.25 & 0.77 \\
\hline $8^{[\mathrm{a}]}$ & 87 & 06.00 & $500 / 1$ & 91 & 380000 & 1.12 & - \\
\hline 9 & 90 & 00.30 & $100 / 1$ & 99 & 15800 & 1.28 & 0.89 \\
\hline 10 & 91 & 00.30 & $100 / 1$ & 99 & 15400 & 1.38 & 0.79 \\
\hline 11 & 92 & 00.05 & $100 / 1$ & 99 & 14500 & 1.36 & 0.70 \\
\hline 12 & 92 & 00.10 & $1000 / 1$ & 91 & 125400 & 1.51 & 0.61 \\
\hline
\end{tabular}

Reactions were performed in Toluene, at $25^{\circ} \mathrm{C}$, [catalyst] $=1 \mathrm{mM}$. [a] Reaction conditions for Nylon- 6 preparation: In toluene at $70^{\circ} \mathrm{C}$, [Catalyst] $=2.5 \mathrm{mM}$. [b] Determined by ${ }^{1} \mathrm{H}$ NMR spectroscopy. [c] Measured by GPC. [d] Determined by analysis of all of the tetrad signals in the methine region of the homonucleardecoupled ${ }^{1} \mathrm{H}$ NMR spectrum.

Complexes 76-84 crystallize in the triclinic space group $P 1$, with two molecules of each compound in their respective unit cells along with half of a THF molecule as the solvent molecule. All the complexes are isostructural to each other owing to the comparable metallic radii of the ions for a six-fold coodrination. ${ }^{\text {71] }}$ In all cases, the bis(P,P-diphenylphosphino-chalcogen amine) ligand is attached to the Ae metal ion through the dative bonds by two amido nitrogen atoms and two sulfur atoms (76-78) or two selenium atoms (79-81) adjacent to the phosphorus atoms. The phosphorus-metal distances in complexes 76-84 are significantly longer than the sum of the covalent radii of the corresponding metal ion and phosphorus atom, which indicates that there is no interaction between the metal ion and the phosphorous atom. Thus, the central metal ion in these complexes virtually adopts a distorted pentagonal bipyramidal geometry, with two selenium atoms and two nitrogen atoms, along with one oxygen atom from the THF molecule situated at the basal plane, and two remaining THF molecules located in the apical positions. It was also noted that the $\mathrm{M}-\mathrm{N}$ distances in all these complexes are relatively short compared to $\mathrm{M}-\mathrm{Se}$ distances, indicating a slight asymmetrical attachment of the tetradentate ligand to the Ae metal ion. The ROP of rac-LA and $\varepsilon-C L$ in the presence of complexes $76-81$ has been systematically studied and reported recently. ${ }^{[5]}$ All the catalysts, in general, showed excellent catalytic activity with precise control over the degree of polymerization and iso- 
selectivity (lactide polymerization). Larger Ae metal ions, in general, resulted in a higher observed rate of polymerization (Ba $>\mathrm{Sr}>\mathrm{Ca}$ ), whereas, for the same set of metal complexes, the highest stereoselectivity was achieved with the smaller Ae ions $(\mathrm{Ca}>\mathrm{Sr}>\mathrm{Ba})$ (Table 6 entry 1-4). The smaller calcium metal ion yielded a polymer with the highest iso-selectivity, whereas the relatively large barium metal ion, under identical reaction conditions, led to the formation of an atactic polymer. This is presumably due to the smaller ionic radii of $\mathrm{Ca}$ where the monomers prefer to enter in a controlled manner, resulting in higher selectivity. Similar observations were also noted while switching from sulfur- to selenium-based complexes. Higher stereoselectivity was achieved from only sulfur-based complexes (76-78) than selenium analogs (79-81). The calcium sulfide complex 76 showed a $P_{\mathrm{i}}$ value of 0.87 , and the calcium selenide complex 79 exhibited a $P_{\mathrm{i}}$ value of 0.81 at $298 \mathrm{~K}$ (Table 6 entry 1 2). The strontium complexes exhibited moderate iso-selectivity. Kinetics study proved that in the case of selenium-based complexes (79-81), there is an overall increase in the rate of polymerization compared to corresponding sulfur-based complexes (76-78). Therefore, from a single catalytic system, it is possible to achieve two different modes of stereoselectivity, either by changing the metal or the nature of the ligand system. Additionally, this is the first example of the phosphoruschalcogen (S, Se) double bond of the catalyst initiating the ROP catalytic cycle in the absence of an external initiator. Complexes 82-84 were tested as catalysts in the ROP of $\varepsilon-C L$ and a high level of activity for the barium complex $\mathbf{7 2}$ was observed, with up to $500 \varepsilon$-CL units successfully converted in good yields within five minutes at $25^{\circ} \mathrm{C}$ with narrow polydispersity.

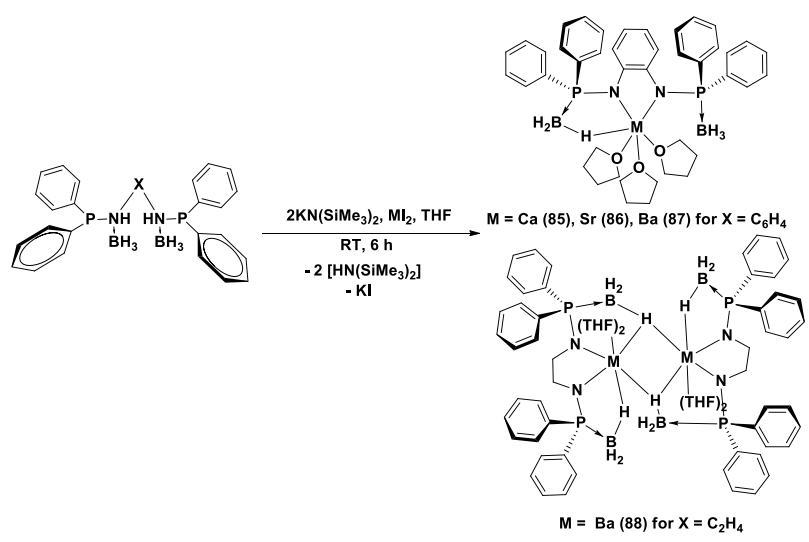

Scheme 9: Bis - $P(B)$-containing alkaline earth metal complexes.

Alkaline earth metal complexes of bis-aminophosphine borane ligand 85-87 (M=Ca, $\left.\mathrm{Sr}, \mathrm{BaX}=\mathrm{C}_{6} \mathrm{H}_{4}\right)$ and $\mathbf{8 8}\left(\mathrm{M}=\mathrm{Ba}, \mathrm{X}=-\mathrm{C}_{2} \mathrm{H}_{4}-\right)$ were synthesized by treating the appropriate ligand with two moles of anhydrous potassium hexamethyldisilazide in THF, followed by the addition of anhydrous Ae metal diiodide $\mathrm{Ael}_{2}(\mathrm{Ae}$ $=\mathrm{Ca}, \mathrm{Sr}, \mathrm{Ba}$ ) to the reaction mixture (Scheme 9). ${ }^{[70,72]}$ Crystals of complexes 85-87 were isolated from a mixture of THF and dioxane solution at $-35{ }^{\circ} \mathrm{C}$, whereas complex 88 was recrystallized from THF and pentane.
Complexes 85-87 crystallize in the triclinic space assemble $P$-1. The dianionic bis(amidodiphenylphosphine borane) ligand is bonded to the Ae metal ion through the chelation of two amido nitrogen atoms and two hydride ions of boranes adjacent to the phosphorus atoms. Each borane $\left(\mathrm{BH}_{3}\right)$ group coordinates through one hydrogen atom, whereas in the case of strontium complex $\mathbf{8 6}$, each borane $\left(\mathrm{BH}_{3}\right)$ group is coordinated through two hydrogen atoms with the active metal center. The phosphorus-metal distances in all the complexes were found to be longer than the total sum of the covalent radii of the comparator metal ion and phosphorus ions, thereby indicating that there is no direct association between them. Thus, the central Ae metal ion in these complexes adopts a distorted pentagonal bi-pyramidal geometry around it, with two boron atoms, two nitrogen atoms, and one oxygen atom from the THF molecule in the basal plane and two remaining THF molecules in the apical positions. Compound $\mathbf{8 8}$ is dimeric, and two barium ions are coordinated by four amido nitrogen atoms and four $\mathrm{BH}_{3}$ groups of two ligands. Out of four borane groups, two are in coordination mode with the two barium ions. Each of the borane $\left(\mathrm{BH}_{3}\right)$ group coordinates through the hydrogen atoms in a $\eta^{1}$ fashion and has a Ba1-B1 bond length of 3.332(6) $\AA$ and Ba1-B2 bond length of 3.251(7) A.. Additionally, two THF molecules are coordinated to each barium ion and the geometry around each barium ion is best described as a distorted bi-pyramidal pentagon. Complexes 85-87 were tested as catalysts in the ROP of rac-LA. In the case of calcium and strontium complexes (85 and 86 ) complete conversion of rac-LA to PLA was achieved in 15 minutes, whereas with the barium complex (87), the complete reaction occurred almost immediately after the catalyst was added (Table 6 entry 5-7). Like other catalysts, the solvent was found to have a profound effect on determining the rate of polymerization. While the reaction in toluene completed almost immediately, using the same barium catalyst (87) it took about three hours to accomplish only $30 \%$ and $25 \%$ conversion when THF and dichloromethane (DCM) respectively were used as solvents. This is due to aggressive coordination of polar solvents with active metal centers, which eventually reduced LA-metal interactions. The molecular weights obtained for all the polymers were in good agreement with their calculated values, supporting the complete activation of the catalyst. In addition, the narrow distribution of molecular weight in all polymers is indicative of excellent control over polymerization with minimal side reactions. In this case also, reactivity of the complexes toward the ROP of rac-LA was closely dependent on the radii of the metal ion and varied in the order of $\mathrm{Ba}>\mathrm{Sr}>\mathrm{Ca}$. All the initiators yielded isotactic PLA with good to moderate $P_{i}$ (0.84-0.71). The PLA obtained from the calcium complex (85) exhibited good iso-selectivity $\left(P_{i}=0.84-0.78\right)$ at room temperature, which is a good result achieved using an achiral Ae initiator. When complex 85 was replaced as an initiator by complexes $\mathbf{8 6}$ and $\mathbf{8 7}$, the degree of iso-selectivity dropped $\left(\mathrm{P}_{\mathrm{i}}=\right.$ $0.80-0.71$ ), as in the previous study (Table 6 entry 5-7). Further, as observed from their $\mathrm{P}_{\mathrm{i}}$ values, selectivity of all the catalysts was found to be quite stable over a wide range of temperatures. The barium complex (88) was not screened for ROP of rac-LA. 
Next, the barium borane complex (87) was also tested as a catalyst for the synthesis of nylon- 6 through the ROP of $\varepsilon$ caprolactam. ${ }^{[73]}$ The current protocol using barium borane complex as a catalyst for ROP of $\varepsilon$-caprolactam provides an efficient and economical way to synthesize nylon-6, since the reaction occurs at a low temperature and without the need for high pressure. The average molecular weight $(\mathrm{Mw})$ obtained for the polymers showed a linear dependency on the monomer to catalyst ratio within an optimum range of mole ratio of the monomer starting from 100:1 to 500:1. (Table 6, entry 8) Controlled experiments combined with the analysis of various reactive intermediates confirmed that the $\sigma$-coordinated boron hydride acts as a mild hydride donor in the first step of the reaction to generate lactamate anions, which then undergo ROP in-situ with the remaining caprolactam molecules under the influence of the dehydrogenated boron metal complex.

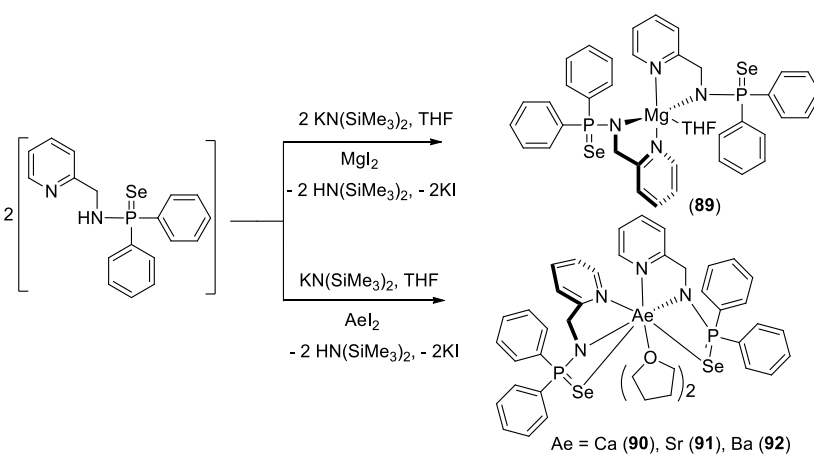

Scheme 10: $\mathrm{P}(\mathrm{Se})$-containing alkaline earth metal complexes.

The Ae metal complexes $89(\mathrm{Mg}), 90(\mathrm{Ca}), 91(\mathrm{Sr})$, and $92(\mathrm{Ba})$ of 2-picolylaminodiphenylphosphane chalcogenide ligand were prepared by following the same procedure (Scheme 10). ${ }^{[58]}$ The crystals of complexes 90 and 91 are poorly diffracting and therefore omitted from the crystal structure analysis. In the magnesium complex 89 , a $\kappa^{2}$-coordination mode of the ligand was observed, leaving the selenium atom as non-coordinated. In addition, a coordinated THF molecule takes the formal coordination number around $\mathrm{Mg}$ to five. Thus, the arrangement around the magnesium ion is an intermediate structure between a square-based pyramidal and trigonal bipyramidal. It is noted that in complex 89, both the pyridine nitrogen and amido nitrogen atoms maintain a trans arrangement to each other through the magnesium ion. In the molecular structure of barium complex $\mathbf{9 2}$, both the ligand fragments exhibited a $\kappa^{3}$ coordination mode using pyridyl, amido nitrogen, and selenium atoms to coordinate with the barium ion. Ligation from the two additional THF molecules makes the Ba center as eightfold coordinated. Thus, the geometry around the barium ion can be best described as a distorted antiprismatic square. It is also noted that in the barium complex (92), both the ligands are bonded to the metal ion in a cis orientation unlike the magnesium complex (89).

All the complexes (89-92) were tested as catalysts for the ROP reaction using 100 equivalents of the rac-LA and $\varepsilon-C L$. The polymerization using complex $\mathbf{9 0}$ and $\mathbf{9 1}$ can be accomplished in toluene at room temperature with a conversion rate of up to $99 \%$ within 30 minutes. In contrast, with the barium complex 92, the reaction proceeded extremely fast, with a conversion rate of $99 \%$ in a mere five minutes (Table 6, entry 9-11). Increasing the monomer loading further, up to 1000 equivalents of the barium complex (92) afforded complete polymerization in 10 minutes with the target molecular weight $(125 \mathrm{~kg} / \mathrm{mol})$, acceptable polydispersity index (PDI) (1.51), and good iso-selectivity (0.61) (Table 6, entry 12). Despite the high overall rates of polymerization, molecular weights of the polymers $(\mathrm{Mn})$ agree well with their calculated values and increase linearly with an increase in the quantity of the monomer, maintaining narrow PDI. These results indicate that all the Ae metal complexes (90-92) are quite effective catalysts in the synthesis of PLAs with high molecular weights without suffering from serious side reactions such as cyclization, transesterification, or even epimerization. All these catalysts, except the barium complex (92), act as very good iso-selective catalysts. In the calcium complex (90), isoselectivities of $\mathrm{P}_{\mathrm{i}}=0.89-0.85$ were achieved when the stoichiometric ratios of [LA]:[90] were varied in the order of 100:1 to $500: 1$, respectively, in toluene at room temperature. The catalytic activity of complexes 90-92 in the ring-opening copolymerization of rac-LA and $\varepsilon$-CL were also examined in terms of conversion and average block length concerning each monomer. Both the barium and strontium complexes showed good activity for the synthesis of copolymers, with the activity of the barium complex (92) being comparatively higher than that of the strontium complex (91), providing polymers with monomodal molecular weight distributions $[\mathrm{PDI}(1)=1.47 ; \mathrm{PDI}(2)=1.38]$. In the case of the calcium complex (90), however, only homopolymerization products were formed. In the barium complex (92), incorporation of LA and CL was in the ratio of 1:0.18 (85:15) during the first 30 minutes, accounting for a relatively higher reactivity of LA compared to that of CL. Upon continuing the reaction for an additional two hours, this ratio was found to improve dramatically to $0.72: 1 \quad(42: 58)$, indicating further incorporation of $\mathrm{CL}$ monomers, producing random copolymers.

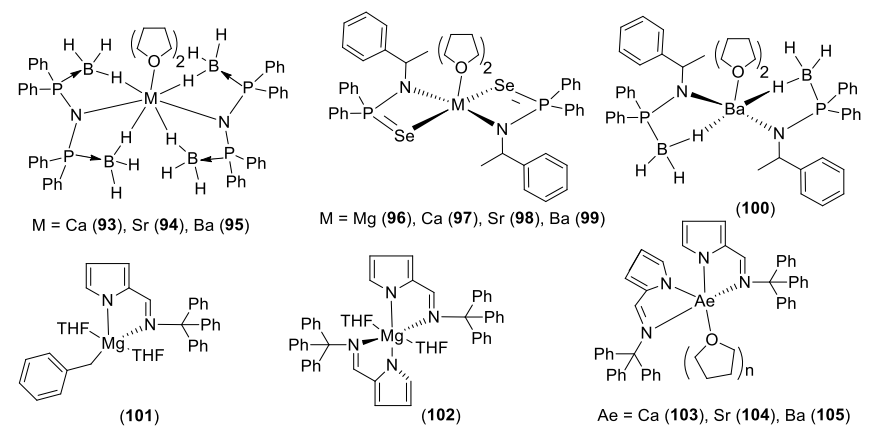

Scheme 11: Bis - $P(S)$ and $P(S e)$-containing alkaline earth metal complexes.

Table 7. Best polymerization results of caprolactone catalyzed by alkaline earth metal complexes of aminophosphine chalcogen and aminophosphine borane ligands. 


\begin{tabular}{|l|l|l|l|l|l|l|}
\hline Entry & Cat & $\begin{array}{l}\text { Time } \\
(\mathrm{h}: \mathrm{m})\end{array}$ & $\begin{array}{l}{[\mathrm{LA}]_{\mathrm{o}} /} \\
{[\mathrm{Cat}]_{0}}\end{array}$ & Con(\%) & $\begin{array}{l}\mathrm{M}_{\mathrm{n}} \mathrm{exp}^{[\mathrm{b}]} \\
\left(\mathrm{gmol}^{-1}\right)^{[\mathrm{c}]}\end{array}$ & PDI \\
\hline 1 & 95 & 00.04 & $700 / 1$ & 83 & 56681 & 1.86 \\
\hline 2 & 98 & 00.15 & $500 / 1$ & 75 & 22261 & 1.04 \\
\hline 3 & 99 & 00.10 & $500 / 1$ & 83 & 32338 & 1.15 \\
\hline 4 & 101 & 00.10 & $200 / 1$ & 90 & 21141 & 1.48 \\
\hline 5 & 102 & 00.15 & $200 / 1$ & 89 & 13781 & 1.59 \\
\hline 6 & 104 & 00.10 & $500 / 1$ & 93 & 86307 & 1.58 \\
\hline 7 & 105 & 00.10 & $600 / 1$ & 98 & 107891 & 1.28 \\
\hline
\end{tabular}

Reactions were performed in Toluene, at $25^{\circ} \mathrm{C}$, [catalyst] $=1 \mathrm{mM},[\mathrm{b}]$ Determined by ${ }^{1} \mathrm{H}$ NMR spectroscopy. [c] Measured by GPC.

Further, our group has reported the syntheses of alkaline earth metal complexes of bis(diphenylphosphino-borane)amido ligand with molecular formulas $\left[\left\{\kappa^{3}-\mathrm{N}\left(\mathrm{PPh}_{2}\left(\mathrm{BH}_{3}\right)\right)_{2}\right\}_{2} \mathrm{M}(\mathrm{THF})_{2}\right][(\mathrm{M}=\mathrm{Ca}$ (93), $\mathrm{Sr}(94), \mathrm{Ba}(95)]$ (Scheme 11). ${ }^{[59]}$ The molecular structure of the barium complex (95) was established by single-crystal X-ray diffraction analysis. In the solid-state structure of complex $95, \kappa^{3}$ coordination mode from the ligand was observed and the barium ion adopted a distorted octahedral geometry. The metal complexes (93-95) were tested as catalysts for the ROP of $\varepsilon-\mathrm{CL}$ and we observed high activity for the barium complex (95) toward the ROP of $\varepsilon-\mathrm{CL}$ with a PDI (Table 7 , entry 1 ). We also described the first-principles calculations in investigating the structure and coordination properties of alkaline earth metal complexes (93-95) as a comparative study between experimental and theoretical findings. Additionally, we have reported a series of enantiomeric pure alkaline earth metal complexes of amidophosphineselenoids $\left[\mathrm{M}\left\{\mathrm{N}\left(R-{ }^{*} \mathrm{CH}(\mathrm{Me}) \mathrm{Ph}\right) \mathrm{P} \quad(\mathrm{Se}) \mathrm{Ph}_{2}\right\}_{2}(\mathrm{THF})_{n}\right]$ or $[\mathrm{M}\{\mathrm{N}(S-$ $\left.\left.\left.{ }^{*} \mathrm{CH}(\mathrm{Me}) \mathrm{Ph}\right) \mathrm{P}(\mathrm{Se}) \mathrm{Ph}_{2}\right\}_{2}(\mathrm{THF})_{\mathrm{n}}\right][\mathrm{M}=\mathrm{Mg}(\mathbf{9 6}), \mathrm{n}=1 ; \mathrm{M}=\mathrm{Ca}(\mathbf{9 7})$, $\mathrm{Sr}(\mathbf{9 8})$ and $\mathrm{Ba}(99), \mathrm{n}=2$ ] and enantiomeric pure barium complexes of amidophosphine-borane ligand $[\mathrm{Ba}\{\mathrm{N}(R-$ $\left.\left.\left.{ }^{*} \mathrm{CH}(\mathrm{Me}) \mathrm{Ph}\right) \mathrm{P}\left(\mathrm{BH}_{3}\right) \mathrm{Ph}_{2}\right\}_{2}(\mathrm{THF})_{2}\right] \quad$ or $\quad\left[\mathrm{Ba}\left\{\mathrm{N}\left(\mathrm{S}-{ }^{*} \mathrm{CH}(\mathrm{Me}) \mathrm{Ph}\right) \mathrm{P}-\right.\right.$ $\left.\left.\left(\mathrm{BH}_{3}\right) \mathrm{Ph}_{2}\right\}_{2}(\mathrm{THF})_{2}\right](\mathbf{1 0 0})$ (Scheme 11). ${ }^{[74]}$ Both the barium and strontium complexes (98 and $\mathbf{9 9}$ ) tested as catalysts in the ROP of $\varepsilon$-CL can convert up to $500 \mathrm{CL}$ units successfully in good yields (80-98\%) within 10 minutes at $25^{\circ} \mathrm{C}$ (Table 7 , entry 2-3). Monoand bis(iminopyrrolyl)magnesium complexes (101 and 102) and heavier alkaline earth metal complexes of the general formula $\left\{(\mathrm{THF})_{n} \mathrm{M}\left(2-\left(\mathrm{Ph}_{3} \mathrm{CN}=\mathrm{CH}\right) \mathrm{C}_{4} \mathrm{H}_{3} \mathrm{~N}\right)_{2}\right\}[\mathrm{M}=\mathrm{Ca}(103), \mathrm{Sr}(104)$, and $\mathrm{n}$ $=2 ; \mathrm{M}=\mathrm{Ba}(105), \mathrm{n}=3$ ] were also prepared using two synthetic methods. In the first, the bulky iminopyrrole ligand was directly treated with the alkaline earth metal precursor $\left[\mathrm{M}\left\{\mathrm{N}\left(\mathrm{SiMe}_{3}\right)_{2}\right\}_{2}(\mathrm{THF})_{n}\right]$ (where $\mathrm{M}=\mathrm{Mg}, \mathrm{Ca}, \mathrm{Sr}$ and $\mathrm{Ba}$ ) in a 2:1 molar ratio in THF at ambient temperature, while in the second, salt metathesis reaction was used, involving the treatment of potassium salt with the corresponding metal diiodides $\mathrm{Ml}_{2}(\mathrm{M}=$ $\mathrm{Ca}, \mathrm{Sr}, \mathrm{Ba}$ ) in a 2:1 molar ratio in THF solvent (Scheme 11). ${ }^{[75]}$ All the alkaline earth metal complexes (103-105) were evaluated as initiators for the ROP of $\varepsilon$-CL. Both the magnesium complexes (101 and 102) showed that they are active in the ROP of $\varepsilon-C L$ at $25^{\circ} \mathrm{C}$ in toluene with a conversion of over $90 \%$ within 15 minutes. However, the heteroleptic $\mathrm{Mg}$ complex (101) is more active than the homoleptic Mg complex (102) (Table 7, entry 4-5). Both strontium and barium analogs (104-105) showed higher reactivity toward the conversion of $\varepsilon-C L$ to PCL than the calcium and magnesium analogs (101-103) and up to $600 \varepsilon$-CL units were successfully converted in high yields (90-98\%) within 5-10 minutes at $25{ }^{\circ} \mathrm{C}$ (Table 7 , entry 6-7). Control over the ROP process was fairly good, affording PCLs, with controlled molar mass values, as well as very narrow dispersity data (PDI < 1.4).

\section{Summary and outlook}

We have set out a detailed study compiling reports of synthesis and catalytic applications of various alkali and alkaline earth metal complexes with different kinds of ligand systems as superior initiators of the ROP of cyclic esters such as $\varepsilon$-caprolactone and rac-LA. In the past various rare earth and heavy metals were considered as a catalyst for achieving high selectivity in polymerization. However, the low abundance and high toxicity of these metals have paved the path for several research groups around the globe to design alternative metal catalysts by combining readily available alkali or alkaline earth metals with various ligand systems. These approaches not only offer an environmentally benign substitute for rare-earth and heavy-metal catalysts but also provide a multifaceted toolbox to manipulate catalyst reactivity and selectivity in a precise and predictable manner. In addition, excellent controls over molecular weights along with minimum side product formation make these catalysts very attractive from the perspective of new and sophisticated material development. In this article, alkali metal complexes are discussed in two sections: crown ether-supported alkali metal complexes and P-based coordinated alkali metal complexes. While both catalysts are found to be efficient in terms of achieving high conversion and high selectivity, a low-temperature requirement of crown ether-supported catalysts can make the process less efficient compared to P-based alkali metal complexes where the reactions are generally carried out at room temperature. Similarly, the alkaline earth metal-based catalysts are explicitly described in three sections: Ae metal complexes with phenoxides and alkoxides, Ae metal complexes with some nitrogen-based ligands, and alkaline earth metal complexes with groups containing $\mathrm{P}(\mathrm{Se}), \mathrm{P}(\mathrm{B})$, and $\mathrm{P}(\mathrm{S})$. While there are quite a few unique catalysts reported from each section exhibiting high activity and selectivity, the requirement of a co-initiator in the first two cases can make these catalysts inferior compared to the third one. Another noteworthy feature differentiating the P-based alkali/alkaline earth metals from the remaining catalysts is their ability to catalyze polymerization through a unique concerted step mechanism where the two ends of the propagating polymer chain remain attached to the active metal center till the polymerization is quenched. These propagating chains are quite stable and can be used for sequential polymerization with other monomers to generate a variety of multi-block copolymers.

The ultimate goal in terms of developing newer catalysts in this field is to achieve syntheses of aliphatic polyesters with broad functional and architectural diversities that can match the comprehensive property profile of synthetic plastics while maintaining appropriate biodegradability and biocompatibility. The broad list of isoselective catalysts that are described herein, can unquestionably provide adequate control over the architecture of the polymers. However, to be able to meet all the required criteria of plastics, much emphasis should be given in terms of rationale design of a new catalyst to introduce more 
functional diversities into these polymers. The research in this area has parallels in many aspects to the advancement of the polyolefin industry, where the development of single-site heterogeneous catalysts has been a major breakthrough in terms of providing access to diverse hydrocarbon-based polymers with precise control on the architecture, stereochemistry, and physical properties. ${ }^{[76,77]}$ Taking this into account, precise synthesis in combination with systematic structural characterization to establish in-depth structure-property correlations for these polymers becomes very important and should be an integral part of the future development of new catalysts.

\section{Acknowledgments}

This work was supported by the Science and Engineering Research Board (SERB), Department of Science and Technology (DST), India, under project no. (EMR/2016/005150).

Keywords: Ring-opening polymerization (ROP) • cyclic ester • rac-LA $\cdot$ alkali metal $\cdot$ alkaline earth metal

[1] R. E. Drumright, P.R. Gruber, D.E. Henton, Adv. Mater. 2000, 12, $1841-$ 1846.

[2] A. C. Albertsson, I.K. Varma, Biomacromolecules 2003, 4, 1466-1486.

[3] I. Manavitehrani, A. Fathi, H. Badr, S. Daly, A.N. Shirazi, F. Dehghani, Polymers 2016, 8, 20-42.

[4] J. de Oliveira, L.P.S. Vandenberghe, S.F. Zawadzki, C. Rodrigues, J.C. de Carvalho, C.R. Soccol, Elsevier, 2017, 633-653.

[5] B.J. O'Keefe, M.A. Hillmyer, W.B. Tolman, J. Chem. Soc., Dalton Trans. 2001, 2215-2224.

[6] O. Dechy-Cabaret, B. Martin-Vaca, D. Bourissou, Chem. Rev. 2004, 104, 6147-6176.

[7] R.H. Platel, L.M. Hodgson, C.K. Williams, Polym. Rev. 2008, 48, 11-63.

[8] J. A. Castillo, D. E. Borchmann, A. Y. Cheng, Y. Wang, C. Hu, A. J. García, M. Weck, Macromolecules 2012, 45, 62-69.

[9] K. Makiguchi, Y. Ogasawara, S. Kikuchi, T. Satoh, T. Kakuchi, Macromolecules 2013, 46, 1772-1782.

[10] R. Todd, G. Rubio, D. J. Hall, S. Tempelaar, A. P. Dove, Chem. Sci. 2013, 4, 1092-1097.

[11] N. Nimitsiriwat, V. C. Gibson, E. L. Marshall, M. R. Elsegood, Dalton Trans. 2009, 3710-3715.

(12) N. Nimitsiriwat, V. C. Gibson, E. L. Marshall, M. R. Elsegood, Inorg. Chem. 2008, 47, 5417-5424.

(13) A. Pilone, K. Press, I. Goldberg, M. Kol, M. Mazzeo, M. Lamberti, J. Am. Chem. Soc. 2014, 136, 2940-2943.

(14) X. Pang, R. Duan, X. Li, X.Chen, Polym. Chem. 2014, 5, 3894-3900.

(15) A. Meduri, T. Fuoco, M. Lamberti, C. Pellecchia, D. Pappalardo, Macromolecules 2014, 47, 534-543.

(16) M. Honrado, A. Otero, J. Fernández-Baeza, L. F. Sánchez-Barba, A. Garcés, A. Lara-Sánchez, A. M. Rodríguez, Organometallics 2014, 33, 1859-1866.

(17) H. Wang, H. Ma, Chem. Commun. 2013, 49, 8686-8688.

(18) W. Yi, H.Ma, Dalton Trans. 2014, 43, 5200-5210.

(19) A. Garcés, L. F. Sánchez-Barba, J. Fernández-Baeza, A. Otero, M. Honrado, A. Lara-Sánchez, A. M. Rodríguez, Inorg. Chem. 2013, 52, 12691-12701.

(20) J. L. Gorczynski, J. Chen, C. L. Fraser, J. Am. Chem. Soc. 2005, 127, 14956-14957.

(21) S. O. Giese, C. Egevardt, A. L. Rüdiger, E. L. Sá, T. A. Silva, S. F. Zawadzki, J. F. Soares, G. G. Nunes, J. Braz. Chem. Soc. 2015, 26, 2258-2268.
(22) B. Gao, X. Li, R. Duan, X.Pang, New J. Chem. 2015, 39, 2404-2408.

(23) C. Tsai, H. Du, J. Chang, B. Huang, B. Ko, C. Lin, RSC Adv. 2014, 4, 14527-14537.

(24) A. F. Douglas, B. O. Patrick, P.Mehrkhodavandi, Angew. Chem. 2008, 120, 2322-2325.

(25) R. H. Platel, A. J. P. White, C. K. Williams, Inorg. Chem. 2011, 50 7718-7728.

(26) B. Liu, T. Roisnel, L. Maron, J. Carpentier, Y. Sarazin, Chem. - Eur. J. 2013 19, 3986-3994.

(27) S. M. Guillaume, L. Maron, P. W. Roesky, Handbook on the Physics and Chemistry of Rare Earths 2014, 44, 1-86.

(28) J. Gao, D. Zhu, W. Zhang, G. A. Solan, Y. Ma and W. H. Sun, Inorg. Chem. Front., 2019, 6, 2619-2652.

[29] Y. Sun, J. Xiong, Z. Dai, X. Pan, N. Tang, and J. Wu, Inorg. Chem. 2016 $55,136-143$.

[30] J. Kadota, D. Pavlović, H. Hirano, A. Okada, Y. Agari, B. Bibal, RSC Adv. 2014, 4, 14725-14732.

[31] M. Oshimura, T. Tang, A. Takasu, J. Polym. Sci., Part A: Polym. Chem. 2011, 49, 1210-1218.

[32] P. Lecomte and C. Jérôme, in Synthetic Biodegradable Polymers, ed. B. Rieger, A. Künkel and G. W. Coates, Springer-Verlag, Berlin Heidelberg, 2012, pp. 173-218.

[33] C. M. Thomas, Chem. Soc. Rev., 2010, 39, 165-173.

[34] O. D. Cabaret, B. M. Vaca, D. Bourissou, Chem. Rev., 2004, 104, 61476176.

[35] X. Zhang, M. Fevre, G. O. Jones, R. M. Waymouth, Chem. Rev., 2018, 118, 839-885;

[36] S. M. Guillaume, E. Kirillov, Y. Sarazin, J. F. Carpentier, Chem. - Eur. J., 2015, 21, 7988-8003;

[37] A. K. Sutar, T. Maharana, S. Dutta, C. T. Chena, C. C. Lin, Chem. Soc. Rev., 2010, 39, 1724-1746;

[38] C. A. Wheaton, P. G. Hayes, B. J. Ireland, Dalton Trans., 2009, 4832-4846.

[39] M. J. Stanford, A. P. Dove, Chem. Soc. Rev., 2010, 39, 486-494.

[40] S. Dagornea, M. Normand, E. Kirillov, J. F. Carpentier, Coord. Chem. Rev., 2013, 257, 1869-1886;

[41] A. B. Kremer, P. Mehrkhodavandi, Coord. Chem. Rev., 2019, 380, 35-57.

[42] D. M. Lyubov, A. O. Tolpygin, A. A. Trifonov, Coord. Chem. Rev., 2019, 392, 83-145.

[43] S. Agarwal, C. Mast, K. Dehnicke, A. Greiner, Macromol. Rapid Commun. 2000, 21, 195-212.

[44] E. Stirling, Y. Champouret, M. Visseaux, Polym. Chem., 2018, 9, 25172531.

[45] P. J. Dijkstra, H. Du, J. Feijen, Polym. Chem., 2011, 2, 520-527.

[46] A. Arbaoui, C. Redshaw, Polym. Chem., 2010, 1, 801-826.

[47] J. Zhang, J. Xiong, Y. Sun, N. Tang, J. Wu, Macromolecules 2014, 47, 7789-7796.

[48] J. Xiong, J. Zhang, Y. Sun, Z. Dai, X. Pan, J. Wu, Inorg. Chem. 2015, 54, 1737-1743.

[49] Z. Dai, Y. Sun, J. Xiong, X. Pan, J. Wu, ACS Macro Lett. 2015, 4, 556-560.

[50] Y. Cui, C. Chen, Y. Sun, J. Wu, X. Pan, Inorg. Chem. Front., 2017, 4, $261-$ 269

[51] Y. Sun, J. Xiong, Z. Dai, X. Pan, N. Tang, J. Wu, Inorg. Chem. 2016, 55, 136-143.

[52] Z. Dai, Y. Sun, J. Xiong, X. Pan, N. Tang, J. Wu, Catal. Sci. Technol., 2016 6, 515-520.

[53] C. Chen, Y. Cui, X. Mao, X. Pan, J. Wu, Macromolecules 2017, 50, 83-96

[54] C. Chen, J. Jiang, X. Mao, Y. Cong, Y. Cui, X. Pan, J. Wu, Inorg. Chem., 2018, 57, 3158-3168.

[55] M. Fernandez-Millan, P. Ortega, T. Cuenca, J. Cano, M. E. G. Mosquera, Organometallics 2020, 39, 2278-2286.

[56] A. Harinath, J. Bhattacharjee, A. Sarkar, T. K. Panda, New J. Chem. 2019, 43, $8882-8891$

[57] J. Bhattacharjee, A. Harinath, H. P. Nayek, A. Sarkar, T. K. Panda, Chem. - Eur. J, 2017, 23, 9319-9331. 
[58] A. Harinath, J. Bhattacharjee, A. Sarkar, H. P. Nayek, T. K. Panda, Inorg. Chem., 2018, 57, 2503-2516.

[59] J. Bhattacharjee, B. S. Mallik, S. Das, T. D. N. Reddy, H. P. Nayek, T. K. Panda, Z. Anorg. Allg. Chem., 2016, 642, 118-127.

[60] (a) M. H. Chisholm, J. C. Gallucci, K. Phomphrai, Chem. Commun., 2003, 48; (b) M. H. Chisholm, J. C. Gallucci, K. Phomphrai, Inorg. Chem. 2004, 43, 6717.

[61] H. Gilman, F. Schulze, J. Am. Chem. Soc., 1926, 48, 2463; (d) H. Gilman, R. N. Meals, G. O’Donnell, L. Woods, J. Am. Chem. Soc., 1943, 65, 268.

[62] L. Clark, G. B. Deacon, C. M. Forsyth, P. C. Junk, P. Mountford, J. P. Townley, J. Wang, Dalton Trans., 2013, 42, 9294.

[63] I. E. Nifant'ev, A. V. Shlyakhtin, V. V. Bagrov, M. E. Minyaev, A. V. Churakov, S. G. Karchevsky, K. P. Birine, P. V. Ivchenko, Dalton Trans., 2017, 46, 12132-12146.

[64] J. Hu, C. Kan, H. Wang, H. Ma, Macromolecules, 2018, 51, 5304-5312.

[65] R. A. Collins, J. Unruangsri, P. Mountford, Dalton Trans., 2013, 42, 759769.

[66] L. F. Sanchez-Barba, A. Garce's, M. Fajardo, C. Alonso-Moreno, J. Fernandez-Baeza, A. Otero, A. Antinolo, J. Tejeda, A. Lara-Sanchez, M. I. Lopez-Solera, Organometallics 2007, 26, 6403-6411.

[67] A. Garce's, L. F. Sanchez-Barba, J. Fernandez-Baeza, A. Otero, M. Honrado, A. Lara-Sanchez, A. M. Rodríguez, Inorg. Chem. 2013, 52, 12691-12701.
[68] M. Honrado, A. Otero, J. Fernandez-Baeza, L. F. Sanchez-Barba, A Garce's, A. Lara-Sanchez, J. Martínez-Ferrer, S. Sobrino, A. M. Rodríguez, Organometallics 2015, 34, 3196-3208.

[69] A. Garce's, L. F. Sanchez-Barba, J. Fernandez-Baeza, A. Otero, A. Lara Sanchez, A. M. Rodríguez, Organometallics 2017, 36, 884-897.

[70] R. K. Kottalanka, A. Harinath, J. Bhattacharjee, H. V. Babu, T. K. Panda Dalton Trans., 2014, 8757-8766.

[71] R. K. Kottalanka, S. Anga, S. K. Jana, T. K. Panda, J. Organomet. Chem. 2013, 740, $104-109$.

[72] J. Bhattacharjee, A. Harinath, A. Sarkar, T. K. Panda, Chem Asian J. 2020 $15,860-866$

[73] J. Bhattacharjee, A. Harinath, A. Sarkar, T. K. Panda, ChemCatChem 2019 11, $3366-3370$

[74] R. K. Kottalanka, A. Harinath, T. K. Panda, RSC Adv., 2015, 5, 3775537767.

[75] R. K. Kottalanka, A. Harinath, S. Rej, T. K. Panda, Dalton Trans., 2015, 44, 19865-19879.

[76] G. W. Coates, Chem. Rev., 2000, 100, 1223-1252.

[77] S. H. Kim, G. A. Somorjai, Proc Natl Acad Sci. 2006, 103, 15289-15294. 
Original article can be read in Chemical Record, 2021, 21, 1898-1911. 